\title{
EVALUASI PROGRAM RELAWAN ANGKATAN MUDA MUHAMMADIYAH PADA PEMULASARAN JENAZAH COVID-I 9 DI KALIMANTAN TENGAH
}

\section{EVALUATION OF MUHAMMADIYAH YOUNG GENERATION VOLUNTEER PROGRAM ON COVID-19 BODY REVIEW IN CENTRAL KALIMANTAN}

\section{Nurul Hikmah Kartini}

FKIP Universitas

Muhammadiyah Palangka Raya,

Palangka Raya, Kalimantan

Tengah, Indonesia

Kata Kunci:

model STAKE, Keputusan,

pemulasaran jenazah

Keywords:

STAKE model, Decision, depicting

the corpse

\section{Accepted}

Maret 202I

Published

April 2021

\begin{abstract}
Abstrak
Kondisi pandemi setahun terakhir menjadi momentum bagi kader-kader Muhammadiyah turut aktif dalam penanggulangan. muhammadiyah melalui para relawannya terjun langsung dilapangan membantu penanganan covif-19. terfokus pada program relawan muhammadiyah pada pemulasaran jenazah, maka tujuan penelitian ini untuk mengevaluasi progam tersebut.

Pendekatan penelitian ini adalah evaluasi program model STAKE yang mana subjek penelitiannya adalah para relawan Muhammadiyah kalimantan tengan. teknik pengumpulan data dari wawancara, observasi dan dokumentasi

Hasil temuan penelitian adalah sebagai berikut: I)Analisis kebutuhan serta tujuan dan sasaran program pada komponen context termasuk kategori baik. 2) Pada komponen process yang dilaksanakan pada program relawan pemulasaran jenazah termasuk dalam kategori baik. 3) Pada komponen outcome termasuk dalam kategori baik.

Keputusan dari hasil evaluasi context, process, outcome pada Program relawan pemulasaran jenazah termasuk kategori baik. artinya bahwa program ini dapat dilanjutkan dengan berbagai perbaikan.
\end{abstract}

\begin{abstract}
The last pandemic condition became a momentum for Muhammadiyah cadres to actively participate in the prevention. Muhammadiyah, through its volunteers, is directly involved in helping the handling of Covif-19. Focused on the Muhammadiyah volunteer program on depicting bodies, the aim of this research is for the program.

The approach of this research is the evaluation of the STAKE program model in which the research subjects are Muhammadiyah volunteers of Central Kalimantan. interview, observation and documentation techniques

The results of the research findings are as follows: I) analysis of the needs and goals and objectives of the program in the context component, including the good category. 2) In the process component carried out in the volunteer monitoring program the bodies are included in the category of bail. 3) On the components, the results are in the good category.
\end{abstract}

decisions from the results of the evaluation of the context, process, results in the volunteer corpse monitoring program were in the good category. meaning that the program could see various improvements. (C) 2021 The Authors. Published by Institute for Research and Community Services Universitas Muhammadiyah Palangkaraya. This is Open Access article under the CC-BY-SA License (http://creativecommons.org/licenses/by-sa/4.0/).

\section{Latar Belakang}

Sebagai sebuah gerakan islam, da'wah ma'ruf nahi munkar dan tajdid, muhammadiyah telah berkembang menjadi sebuah organisasi modern dengan struktur yang tidak sederhana dan program kegiatan yang tidak sedikit. Mengingat besar dan beratnya misi muhammadiyah itu, maka dibutuhkan dukungan yang besar pula dari kader-kader Muhammadiyah. Vitalnya sebuah pengkaderan digambarkan oleh pernyataan Prof. Dr. H.A. Mukti Ali bahwasanya "Baik- buruknya muhammadiyah pada masa yang akan datang dapat dilihat dari baik- buruknya pendidikan kader yang sekarang dilakukan”. Jika pendidikan kader 
Nurul Hikmah Kartini. Evaluasi Program Relawan Angkatan Muda Muhammadiyah Pada Pemulasaran Jenazah Covid-19 Di Kalimantan Tengah

Muhammadiyah sekarang ini baik, maka Muhammadiyah pada masa yang akan datang akan baik, sebaliknya apabila jelek, maka Muhammadiyah pada masa yang akan datang juga jelek.” Karena bagaimanapun juga dengan keterbatasan umur dan kemampuan manusia Transformasi nilai-nilai PersyarikatanMuhammadiyah harus tetap terjamin sampai ke setiap warganya baik dilevel Pimpinan, Kader, anggota bahkan simpatisan sekalipun. Tanpa adanya transformasi nilai yang baik dijamin sebuah organisasi akan runtuh secara perlahan karena tidak ada yang meneruskannya.

Kondisi Pandemi Covid-19 menuntut kader-kader Muhammadiyah untuk turut berpartisipasi secara kreatif dan inovatif dalam penanggulangan pandemi ini sebagai bentuk pengabdian kepada masyarakat. Berdasarkan hasil observasi awal, kader-kader Muhammadiyah yang tergabung dalam Relawan Muhammadiyah banyak terlibat aktif dalam penanganan covid-19, baik secara langsung maupun secara tidak langsung. Secara khusus, beberapa anggota relawan Muhammadiyah turut membantu kegiatan seperti Penyemprotan, pembagian masker, pembagian sembako dan membantu proses pemulasaran jenazah. Dari 13 kabupaten/kota di Kalimantan Tengah, secara nyata terlihat ada 2 (dua) kabupaten yaitu Kota Palangkaraya dan Kabupaten Kapuas yang relawan Muhammadiyahnya terlibat langsung dalam pemulasaran jenazah. Sebagai bentuk pelayanan kepada masyarakat, program relawan Muhammadiyah ini perlu dievaluasi secara mendalam untuk peningkatan kualitas layanan yang lebih baik.

\section{METODE PENELITIAN}

\section{Waktu dan Tempat Penelitian}

Penelitian ini direncanakan dilaksanakan dari bulan Juli sampai dengan desember 2020. Lokasi penelitian di kota Palangkaraya dan kabupaten Kapuas. Namun karena kondisi pandemi, maka keperluan data diluar kota akan diperoleh dengan cara daring.

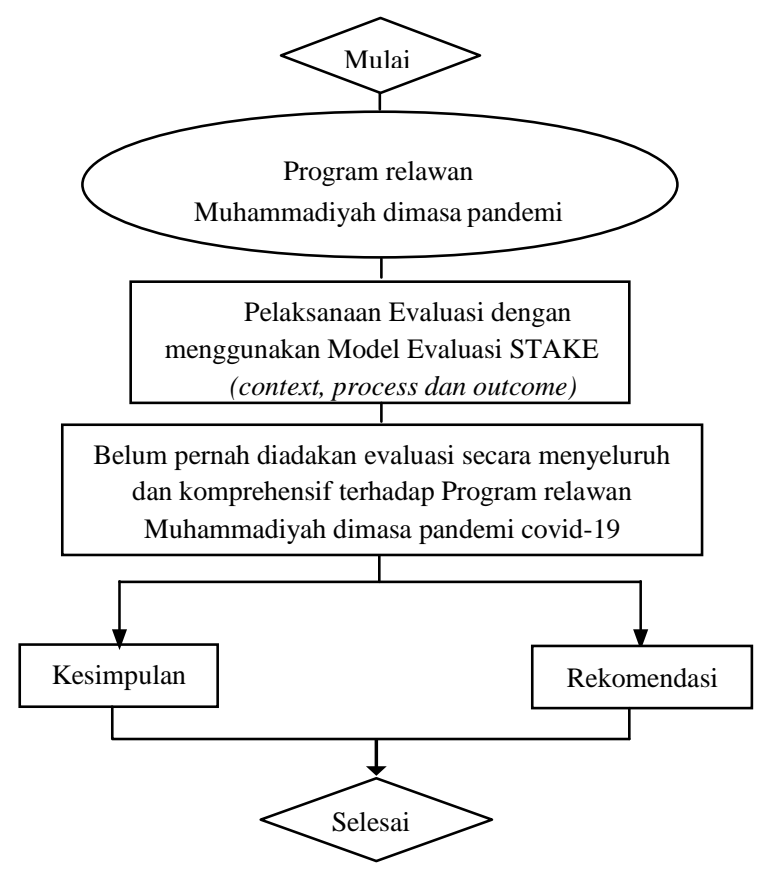

Gambar 3.I. Diagram Alir Penelitia 


\section{Pendekatan, Metode dan Desain Penelitian}

Pendekatan yang digunakan dalam penelitian ini dengan model evaluasi STAKE. Metode penelitian yang digunakan adalah penelitian kualitatif yaitu penelitian tentang data yang dikumpulkan dan dinyatakan dalam bentuk kata-kata dan gambar. Kata-kata disusun dalam kalimat misalnya, kalimat hasil wawancara antara peneliti dan informan. Model evaluasi STAKE ini memberdayakan tiga tahap dalam evaluasi program yaitu (I) anteseden (antecedents/ context), (2) transaksi (transaction/ process), dan (3) keluaran (output- outcomes).

Sampel dalam penelitian ini adalah para relawan Muhammadiyah yang terlibat langsung dalam pemulasaran jenazah covid-19, baik di kota Palangkaraya maupun di kabupaten Kapuas. Desain Penelitian dapat dilihat pada gambar 3.2. berikut ini.

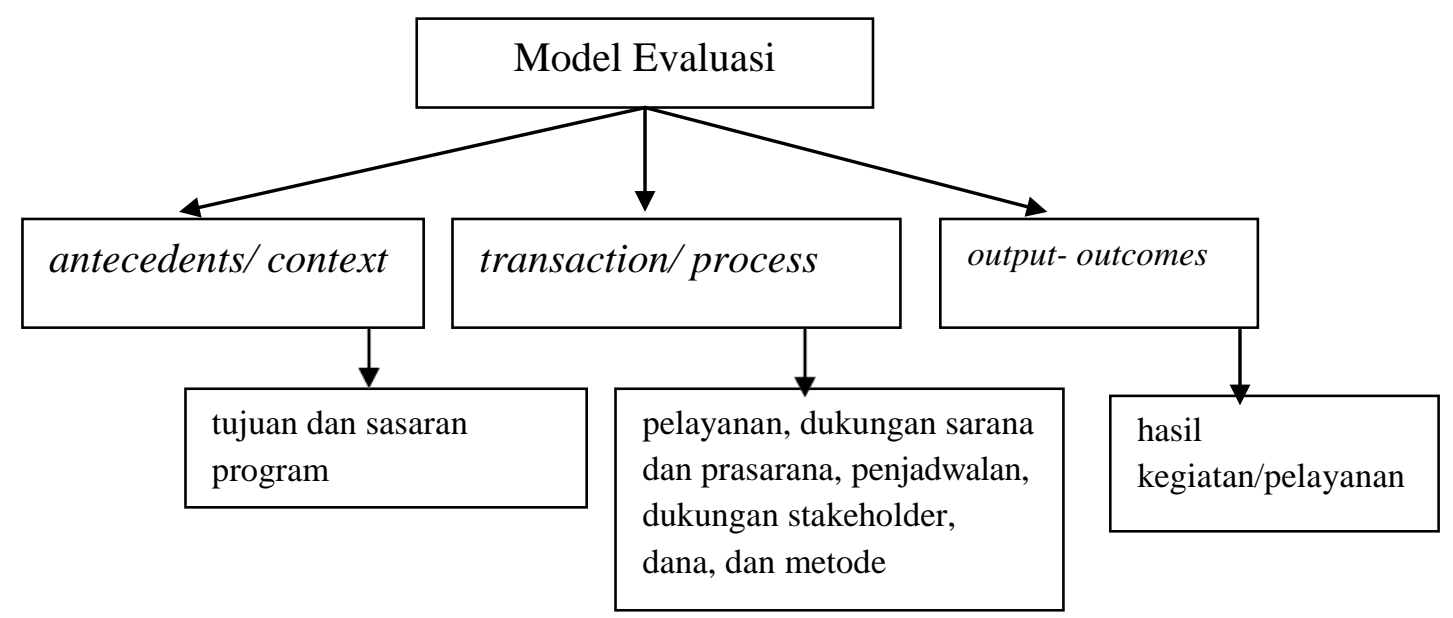

Gambar 3.2. Desain Penelitian Model Evaluasi STAKE

\section{Teknik Analisis Data}

Teknik analisis data dengan menggunakan analisis deskriptif berfungsi untuk menganalisis data hasil penelitian dalam bentuk yang sederhana sehingga mudah mendapatkan gambaran hasil penelitian. Sementara itu, data yang diperoleh dari observasi dan wawancara akan dianalisis secara kualitatif, bertujuan agar peneliti dapat mendeskripsikan dan menjelaskan pola hubungan yang hanya dapat dilakukan dengan seperangkat konsep yang spesifik.

Reduksi data, penyajian data, dan penarikan kesimpulan dalam tahapan analisis data kualitatif di atas dapat dilihat pada gambar 3.3 berikut ini 


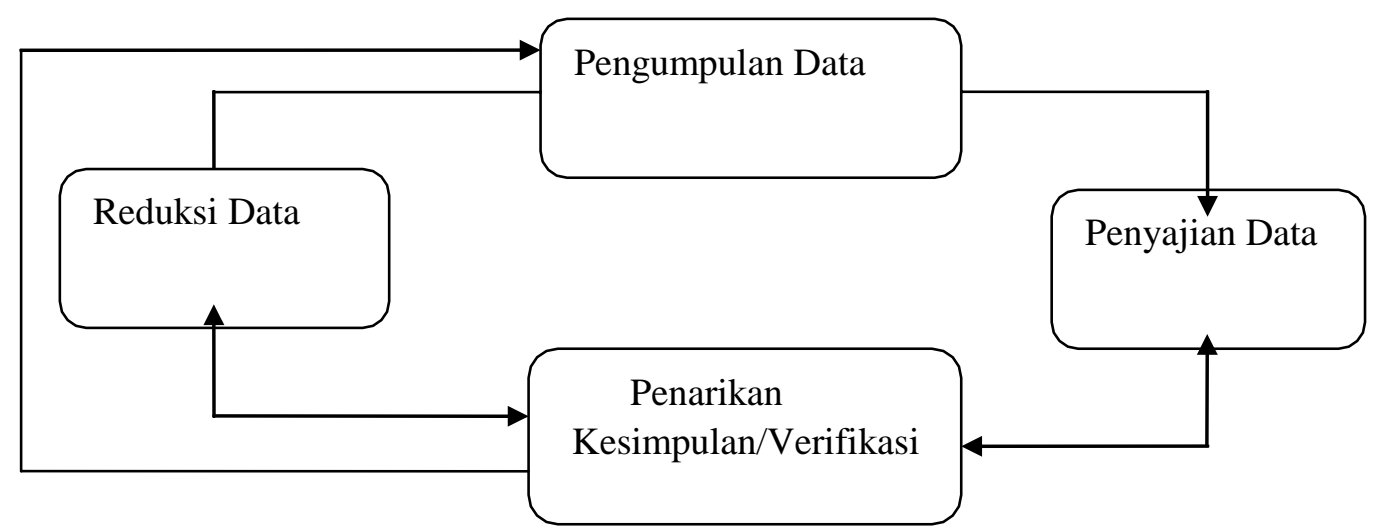

Gambar 3.3. Bagan Analisis Data Interaktif (Emzir, 2008: 56)

\section{Pemeriksaan Keabsahan Data}

Pemeriksaan keabsahan data sangat diperlukan dalam penelitian kualitatif demi keshahihan dan keandalan serta tingkat kepercayaan data yang telah terkumpul. Pemeriksanaan keabsahan data melalui tahapan: kredibilitas, transferabilitas, dependabilitas, konfirmabilitas.

\section{Hasil Penelitian}

Tabel I

Hasil Evaluasi dengan kriteria evaluasi

\begin{tabular}{|c|c|c|}
\hline Kriteria Evaluasi & Temuan Evaluasi & Kesimpulan \\
\hline $\begin{array}{l}\text { Actedents : tujuan dan } \\
\text { sasaran program }\end{array}$ & $\begin{array}{l}\text { I. Pada bagian tujuan dan sasaran program } \\
\text { yakni terdapat kesesuaian dengan tujuan dan } \\
\text { sasaran program Muhammadiyah. Dalam ha } \\
\text { ini MDMC (Muhammadiyah Disaster } \\
\text { Management Centre) }\end{array}$ & $\begin{array}{l}\text { Kriteria evaluasi pada tujuan sudah } \\
\text { mencapai } 80 \% \text {, dan sasaran program sudah } \\
\text { mencapai } 80 \% \text {. }\end{array}$ \\
\hline \multirow[t]{2}{*}{$\begin{array}{l}\text { Transaction/process: } \\
\text { pelayanan, dukungan } \\
\text { sarana dan prasarana, } \\
\text { penjadwalan, dukungan } \\
\text { stakeholder, dana, dan } \\
\text { metode }\end{array}$} & $\begin{array}{l}\text { Pada bagian transaction yang hasil evaluasi } \\
\text { nya tergambar berikut ini: } \\
\text { a. Pelayanan } \\
\text { b. Dukungan sarana dan prasarana } \\
\text { c. Jadwal } \\
\text { d. Dukungan stakeholder } \\
\text { e. Dana } \\
\text { f. metode }\end{array}$ & $\begin{array}{l}\text { Kriteria evaluasi pada process } \\
\text { mencapai: } \\
\text { a. } 80 \% \text { Pelayanan } \\
\text { b. } 100 \% \text { Dukungan sarana dan } \\
\text { prasarana } \\
\text { c. } 100 \% \text { Jadwal } \\
\text { d. } 40 \% \text { pada Dukungan stakeholder } \\
\text { e. } 80 \% \text { pada Dana } \\
\text { f. } 80 \% \text { metode }\end{array}$ \\
\hline & $\begin{array}{l}\text { Pada bagian outcomes yang hasil evaluasi } \\
\text { didasarkan pada kegiatan pelayanan sudah } \\
\text { maksimal dilaksanakan }\end{array}$ & $\begin{array}{l}\text { Kriteria evaluasi } \quad \text { pada hasil } \\
\text { kegiatan/pelayanan sudah mencapai } 100 \% .\end{array}$ \\
\hline
\end{tabular}




\section{Pembahasan}

Hasil yang diperoleh dipaparkan temuan-temuan hasil evaluasi kedalam tiga bagian model evaluasi yaitu: context, process, dan outcome. Hasil penelitian ini diperoleh dari teknik pengumpulan data dari wawancara, observasi, dan dokumentasi. Hasil penelitian tersebut dibahas secara berurutan sebagai berikut:

\section{Evalusi Context}

Pada tahapan evaluasi ini, peneliti menggali data dan informasi yang terkait analisis kebutuhan serta tujuan dan sasaran program. Data diperoleh melalui wawancara. Wawancara diberikan kepada relawan Angkatan Muda Muhammadiyah yang tergabung dalam MDMC di kota Palangkaraya. Pertanyaan yang mendasari evaluasi konteks ada dua yaitu: I) Apakah program ini sesuai dengan kebutuhan persyarikatan Muhammadiyah?, 2) Apakah tujuan dan sasaran program ini dengan tujuan pergerakan Muhammadiyah?.

Berdasarkan hasil wawancara diperoleh jawaban bahwa Persyarikatan pastinya melakukan analisis kebutuhan setiap membuat sebuah program apapun itu. Relawan ini sebagai wujud bentuk pengabdian di amal usaha Muhammadiyah.

Di era pandemi covid-19 perlu kerjasama semua pihak dalam penanganan pandemi ini

Program yang baik harus memiliki kesesuaian dengan tujuan persyarikatan diatasnya yang menaungi keberadaan lembaga tersebut. Adanya diharapkan mampu mencapai tujuan yang diinginkan secara bersama-sama.

Tabel 2. Hasil Evaluasi Context

\begin{tabular}{|c|c|c|}
\hline Kriteria Evaluasi & Temuan Evaluasi & Kesimpulan \\
\hline $\begin{array}{l}\text { Adanya analisis kebutuhan } \\
\text { Program } \\
\text { Kesesuaian tujuan dan } \\
\text { sasaran program dengan Visi, } \\
\text { misi, serta Tujuan amal usaha } \\
\text { persyarikatan Muhammadiyah }\end{array}$ & $\begin{array}{l}\text { Adanya analisis kebutuhan sebelum } \\
\text { dibuat program relawan } \\
\text { I. Adanya kesesuaian antara tujuan } \\
\text { dan sasaran program dengan Visi } \\
\text { Persyarikatan } \\
\text { 2. Adanya kesesuaian antara tujuan } \\
\text { dan sasaran program dengan Misi } \\
\text { Persyarikatan } \\
\text { 3. Adanya kesesuaian tujuan dan } \\
\text { sasaran program dengan tujuan } \\
\text { Persyarikatan }\end{array}$ & $\begin{array}{l}\text { Tercapai } 100 \% \text { dengan kategori } \\
\text { "baik sekali” } \\
\text { Tercapai } 100 \% \text { dengan kategori } \\
\text { "baik sekali” }\end{array}$ \\
\hline
\end{tabular}

Pastinya kehadiran para relawan yang tergabung dalam MDMC banyak memberi manfaat bagi umat khususnya di Kalimantan Tengah. Sinergitas dengan persyarikatan semakin mengukuhkan relawan Muhammadiyah menjadi terdepan dalam program relawan penanganan covid-I9. 
Nurul Hikmah Kartini. Evaluasi Program Relawan Angkatan Muda Muhammadiyah Pada Pemulasaran Jenazah Covid-19 Di Kalimantan Tengah

2. Evaluasi Process

Komponen yang dievaluasi pada tahapan ini ada enam

bagian yaitu: Pelayanan, Dukungan sarana dan prasarana, Jadwal,

Dukungan stakeholder, Dana dan metode. Secara umum, hasil evaluasi process terlihat pada tabel 3. berikut ini.

Tabel 3. Hasil Evaluasi Process

\begin{tabular}{|c|c|c|}
\hline Kriteria Evaluasi & Temuan Evaluasi & Kesimpulan \\
\hline Bentuk Pelayanan & $\begin{array}{l}\text { Pelayanan pada pemulasaran jenazah dimulai } \\
\text { dari memandikan, mengkafani, } \\
\text { mensholatkan sampai menguburkan }\end{array}$ & $\begin{array}{l}\text { Tercapai } 80 \% \text { dengan kategori } \\
\text { "baik" }\end{array}$ \\
\hline Tersedianya sarana dan prasarana & $\begin{array}{l}\text { Sarana dan prasarana sudah memadai } \\
\text { karena sudah disediakan oleh Rumah Sakit }\end{array}$ & $\begin{array}{l}\text { Kriteria evaluasi terpenuhi, } \\
\text { penilaian 100\% dengan kategori } \\
\text { "baik sekali" }\end{array}$ \\
\hline Adanya jadwal & $\begin{array}{l}\text { Adanya jadwal yang terprogram dengan } \\
\text { baik }\end{array}$ & $\begin{array}{l}\text { Kriteria evaluasi terpenuhi, } \\
\text { penilaian } 80 \% \text { dengan kategori } \\
\text { "baik" }\end{array}$ \\
\hline Dukungan stakeholder & $\begin{array}{l}\text { I. Dukungan penuh dari persyarikatan } \\
\text { 2. Masih terdapat kendala pemahaman } \\
\text { mengkomunikasikan dengan keluarga } \\
\text { korban yang meninggal }\end{array}$ & $\begin{array}{l}\text { Kriteria evaluasi terpenuhi, } \\
\text { penilaian } 60 \% \text { dengan kategori } \\
\text { "cukup" }\end{array}$ \\
\hline Tersedianya dana & $\begin{array}{l}\text { Ketersediaan dana sudah memenuhi untuk } \\
\text { kegiatan logistic dan lapangan }\end{array}$ & $\begin{array}{l}\text { Kriteria evaluasi terpenuhi, } \\
\text { penilaian } 80 \% \text { dengan kategori } \\
\text { "baik }\end{array}$ \\
\hline Metode & $\begin{array}{l}\text { Adanya panduan dari PP Muhammadiyah } \\
\text { untuk pemulasaran jenazah }\end{array}$ & $\begin{array}{l}\text { Kriteria evaluasi terpenuhi, } \\
\text { penilaian } 100 \% \text { dengan kategori } \\
\text { "baik }\end{array}$ \\
\hline
\end{tabular}

Pada kategori process, relawan pemulasaran jenazah sudah bekerja dengan baik sesuai SOP. Di kota Palangkaraya, selama kurang lebih 8 (delapan) bulan sudah melakukan pemulasaran jenazah kurang lebih 80 orang. Jenazah yang teridentifikasi covid-19 dimakamkan secara protokol kesehatan berasal dari Rumah Sakit Doris Sylvanus, RSI PKU Muhammadiyah, dan rumah sakit swasta lainnya. Buku panduan sudah tersedia secara nasional yang dikeluarkan oleh PP MUhammadiyah. Adanya dukungan penuh sarana dan prasarana memperlancar kegiatan. APD yang lengkap sudah tersedia, begitupun ambulance sudah tersedia di PWM-Lazismu. MDMC juga memiliki akun media sosial yang memuat berita-berita tentang pelaksanaan kegiatan relawan Muhammadiyah dimasa pandemi ini.
Berdasarkan wawancara dengan tim relawan, masih ada beberapa saran masukan berupa: belum tersediany sekretariat MDMC yang tetap, selama ini teman-teman relawan ikut berkantor di BPBD Kota Palangkaraya. Kendala yang sering dihadapi dilapangan adalah bentuk komunikasi, memberikan pemahaman kepada keluarga korban. Bahkan ada I(satu) kejadian yang sempat terekspos secara nasional terkait pemukulan terhadap relawan yang melakukan pemulasaran jenazah dengan keluarga korban.

\section{Evaluasi Outcome}

Evaluasi outcome adalah capaian dan kompetensi yang dimiliki oleh relawan. Hasil secara umum terlihat pada tabel 4 . berikut ini.

Tabel 4. Hasil Evaluasi Outcome

\begin{tabular}{lcc}
\hline Kriteria Evaluasi & Temuan Evaluasi & Kesimpulan \\
\hline Relawan yang bertugas telah mengikuti & Adanya sertifikat pelatihan. & Kriteria tercapai \\
pelatihan yang diadakan oleh Pimpinan & pada kategori $80 \%$ \\
Wilayah Muhammadiyah & & pada kategori baik. \\
\hline
\end{tabular}


Para relawan yang terjun sudah mengikuti pelatihan pemulasaran jenazah yang diselenggarakan oleh Pimpinan Wilayah Muhammadiyah, jadi meskipun memiliki panduan, mereka juga dilatih secara prakter agar saat pelaksanaan di lapangan berjalan sesuai dengan standar yang telah ditetapkan

\section{KESIMPULAN}

Kesimpulan penelitian adalah sebagai berikut:

I. Analisis kebutuhan serta tujuan dan sasaran program pada komponen context termasuk kategori baik.

2. Pada komponen process yang dilaksanakan pada program relawan pemulasaran jenazah termasuk dalam kategori baik.

3. Pada komponen outcome termasuk dalam kategori baik.

Keputusan dari hasil evaluasi context, process, outcome pada Program relawan pemulasaran jenazah termasuk kategori baik. Artinya bahwa Program ini dapat dilanjutkan dengan berbagai perbaikan.

\section{REKOMENDASI}

Berdasarkan kesimpulan yang dijabarkan diatas, maka peneliti menetapkan beberapa rekomendasi dalam rangka perbaikan dalam Program Baitul Arqam sebagai berikut:

I. Dari sisi context, perlu adanya konsistensi dalam melaksanakan kebijakan yang sesuai dengan analisis kebutuhan serta tujuan dan sasaran program guna peningkatan mutu sumber daya manusia.

2. Dari sisi process, maka perlu perbaikan yaitu: Perlunya sekretariat tetap untuk para relawan yang bertugas dibawah naungan MDMC.
3. Dari sisi outcome, hal yang dapat direkomendasikan adalah konsistensi pelaksanaan dukungan Persyarikatan terhadap para relawan yang bertugas.

\section{DAFTAR PUSTAKA}

Daniel L.Stufflebeam dan Anthony J. Shinkfield. Evaluation Theory, Models, \& Applications. United States of America: A Wiley Imprint. 2007

Darmadi, Hamid. Metode Penelitian Pendidikan dan Sosial. Bandung: Alfabeta. 2013

Djaali\&Pudji Muljono. Pengukuran dalam Bidang Pendidikan. Jakarta: PT. Grasindo. 2008

Furqan, Arief. Pengantar Penelitian dalam Pendidikan. Surabaya: Usaha Nasional. 2000

Hartoyo. Pengembangan Instrumen Kompetensi Penilik dan Penerapannya di Kabupaten Musi Rawas. Jurnal Penelitian dan Evaluasi Pendidikan, Nomor I, Tahun VIII. 2006

Mardapi, Djemari. Pengukuran Penilaian \& Evaluasi Pendidikan. Yogyakarta: Nuha Medika. 2012.

Muhtadi, Ali. Penanaman Nilai-Nilai Agama dalam Pembentukan Sikap dan Perilaku Siswa Sekolah Dasar Islam Terpadu Luqman Al-Hakim Yogyakarta. Jurnal Penelitian dan Evaluasi Pendidikan, Nomor I, Tahun VIII. 2006.

Muyasaroh, Sutrisno. Pengembangan Instrumen Evaluasi Cipp Pada Program Pembelajaran Tahfiz Alqur'an Di Pondok Pesantren. Jurnal Penelitian dan Evaluasi Pendidikan, Volume 18, Nomor 2, 215-233. 2014.

N. H. Kartini, "Evaluasi Program Baitul Arqam Bagi Karyawan Di Universitas Muhammadiyah Palangkaraya", anterior, vol. 16, no. 2, Pp. I44I57, Jun. 2017. 